\title{
ORIENTAÇÃO PARA O MERCADO: ANTECEDENTES E CONSEQÜÊNCIAS
}

\section{RESUMO}

Esta pesquisa aborda três perguntas: (1) Por que algumas organizações são mais voltadas para o mercado do que outras? (2) Que efeito essa orientação para o mercado tem sobre os funcionários e o desempenho da empresa? (3) O elo entre a orientação para o mercado e o desempenho da empresa depende do contexto ambiental? As conclusões de duas amostras de âmbito nacional sugerem que a orientação para o mercado está relacionada com a ênfase que a alta administração dá à orientação, com a aversão dos principais gestores ao risco, com conflitos e ligações interdepartamentais, com a centralização e com a orientação do sistema de recompensas. Ademais, as conclusões sugerem que a orientação para o mercado está relacionada com o desempenho empresarial (mas não com o market share) geral (subjetivo), com o compromisso dos funcionários com a organização, e com o espírito de classe. Finalmente, a ligação entre a orientação para o mercado e o desempenho parece ser muito forte em quaisquer contextos ambientais caracterizados por diversos graus de turbulência no mercado, intensidade competitiva e turbulência tecnológica.

\section{Bernard J. Jaworski}

Marketspace

\section{Ajay K. Kohli}

Emory University

\begin{abstract}
This research addresses three questions: (1) Why are some organizations more market-oriented than others? (2) What effect does a market orientation have on employees and business performance? (3) Does the linkage between a market orientation and business performance depend on the environmental context? The findings from two national samples suggest that a market orientation is related to top management emphasis on the orientation, risk aversion of top managers, interdepartmental conflict and connectedness, centralization, and reward system orientation. Furthermore, the findings suggest that a market orientation is related to overall (judgmental) business performance (but not market share), employees' organizational commitment, and esprit de corps. Finally, the linkage between a market orientation and performance appears to be robust across environmental contexts that are characterized by varying degrees of market turbulence, competitive intensity, and technological turbulence.
\end{abstract}

PALAVRAS-CHAVE Orientação para o mercado, desempenho organizacional, contexto ambiental, compromisso dos funcionários, espírito de classe.

KEYWORDS Market orientation, business performance, environmental context, employees' organizational commitment, esprit de corps. 


\section{INTRODUÇÃo}

Nos últimos anos tem-se dado ênfase renovada ao fornecimento de produtos e serviços de qualidade superior aos clientes (por exemplo, Bitner, 1990; Day e Wensley, 1988; Parasuraman, Zeithaml e Berry, 1985). Como as necessidades e expectativas dos clientes estão sempre evoluindo, fornecer consistentemente produtos e serviços de alta qualidade exige constante acompanhamento e adaptação às necessidades do mercado, ou seja, orientação para o mercado. Em termos mais formais, orientação para o mercado significa a geração da inteligência de mercado na empresa como um todo, a disseminação da inteligência entre os departamentos e a reação de toda a organização a essa inteligência (veja Kohli e Jaworski, 1990).

Por que algumas organizações são mais voltadas para o mercado do que outras? É interessante observar que essa questão crucial até hoje não foi abordada por um estudo empírico. Kohli e Jaworski (1990) aventaram recentemente diversas proposições quanto aos antecedentes da orientação para o mercado. Mas como indicam os autores, essas proposições exigem validação empírica.

Ademais, embora se admita que a orientação para o mercado leve à maior satisfação do cliente e ao maior comprometimento dos empregados com a organização, essas relações jamais foram submetidas a testes empíricos. Narver e Slater (1990) proporcionam um avanço ao relatar apoio empírico à relação freqüentemente presumida ou implícita entre a orientação para o mercado e o desempenho. Mas há na literatura argumentos que sugerem que a orientação para o mercado pode ter efeito forte ou fraco sobre o desempenho da empresa, dependendo de condições ambientais como turbulência do mercado e intensidade da competição (por exemplo, veja Houston, 1986). Tais variações potenciais do impacto da orientação para o mercado sobre o desempenho ainda não foram investigadas empiricamente.

O objetivo desta pesquisa é preencher as lacunas de conhecimento indicadas acima. Mais especificamente, são investigadas duas amostras de âmbito nacional para determinar (1) o efeito de três conjuntos de fatores aventados na literatura sobre a orientação para o mercado, (2) o efeito hipotético da orientação para o mercado sobre o desempenho empresarial e os empregados, e (3) o papel das características ambientais na moderação da relação entre orientação para o mercado e desempenho competitivo. Esta pesquisa esclarece a importância relativa de diversos fatores organi- zacionais que se pressupõe ajudam ou atrapalham a orientação para o mercado, assim como a natureza do impacto da orientação sobre os empregados e o desempenho da empresa.

Além de testar a teoria, as conclusões da pesquisa são úteis para gestores que estejam envidando esforços de mudança que tenham por objetivo construir organizações orientadas para o mercado (veja também Day, 1990). A pesquisa aborda ainda empiricamente a questão de saber se todas as empresas devem se concentrar numa orientação para o mercado. Trata-se de uma consideração importante na medida em que a inversão de recursos ao desenvolvimento de uma orientação para o mercado pode se revelar um desperdício se tal orientação deixar de levar ao melhor desempenho em determinados ambientes empresariais, como aqueles em que a intensidade da competição é baixa. Finalmente, esta pesquisa esclarece o impacto da orientação para o mercado sobre os funcionários de uma organização, aspecto da orientação para o mercado que tem recebido pouca ênfase em artigos anteriores.

Em primeiro lugar, forneceremos uma breve revisão da literatura sobre a orientação para o mercado, e discutiremos hipóteses ligadas aos antecedentes e às conseqüências de tal orientação. Embora se possa afirmar que fatores organizacionais, tanto internos quanto externos (como intensidade da competição), sejam antecedentes da orientação para o mercado (veja Lusch e Laczniak 1987), o presente estudo se concentra nos fatores internos. Em seguida, descreveremos duas investigações de campo de grande escala realizadas para testar essas hipóteses. Depois discutiremos os resultados da pesquisa. O estudo termina com uma discussão da importância administrativa das conclusões e com sugestões para pesquisas futuras.

\section{HISTÓRICO E HIPÓTESES}

Introduzido no início da década de 1950, o conceito de marketing (o arcabouço filosófico da orientação para o mercado) representa uma das pedras fundamentais do pensamento em marketing (veja Borch, 1957; McKitterick, 1957). Mas, dada sua notória importância, é surpreendente que tão pouca pesquisa tenha sido dedicada ao assunto. Há apenas um pequeno conjunto de artigos conceituais que oferecem sugestões preliminares para a construção de uma orientação para o mercado (como Felton, 1959; Stampfl, 1978; Webster, 1988). E os poucos estudos empíricos que foram rea- 
lizados sobre o assunto dedicam-se a saber qual a extensão da adoção do conceito de marketing pelas organizações e não seus antecedentes ou as conseqüências de uma orientação para o mercado (por exemplo, Barksdale e Darden, 1971; Hise, 1965; Lusch, Udell e Laczniak, 1976; McNamara, 1972). Mas o interesse acadêmico e prático na orientação para o mercado tem ressurgido com vigor (por exemplo, Deshpande e Webster, 1989; Deshpande, Farley e Webster, 1993; Houston, 1986; Narver e Slater, 1990; Olson, 1987; Linden, 1987; Shapiro, 1988).

Usando a abordagem de "teorias em uso" descrita por Zaltman, LeMasters e Heffring (1982), Kohli e Jaworski (1990) definem a orientação para o mercado como sendo composta de três conjuntos de atividades: (1) geração, em toda a empresa, de inteligência de mercado sobre as necessidades atuais e futuras dos clientes; (2) disseminação da inteligência entre os departamentos; e (3) prontidão [responsiveness] da empresa a essa inteligência. Além disso, define-se o componente de prontidão como sendo composto de dois conjuntos de atividades: concepção da resposta (ou seja, uso da inteligência de mercado para o desenvolvimento de planos) e implementação da resposta (ou seja, execução de tais planos). Essa definição se concentra em comportamentos específicos e, portanto, facilita a operacionalização do construto da orientação para o mercado.

A conceitualização em três componentes também permite uma análise mais focada no papel de qualquer antecedente de uma orientação para o mercado. (Como veremos mais adiante, o mesmo antecedente por ter efeitos opostos sobre os diferentes componentes da orientação para o mercado.) Assim, para fins do presente estudo, os autores adotam a conceitualização em três componentes da orientação para o mercado. É útil observar que tradicionalmente os clientes foram considerados o principal foco da orientação para o mercado. Como fizeram Lusch e Laczniak (1987), adotamos uma perspectiva mais ampla, em que se considera que outras forças do mercado, como competição, tecnologia e regulação, também pertencem ao domínio do construto orientação para o mercado.

Para conduzir a discussão que se segue, fornecemos uma figura que identifica os principais construtos envolvidos no estudo (veja a Figura 1). Com base na literatura discutida adiante, lançamos a hipótese de que três conjuntos de antecedentes relacionados à alta administração, a fatores interdepartamentais e aos sistemas organizacionais estejam relacionados com a orientação para o mercado. Adotamos ainda a hipótese de que a orientação para o mercado está relacionada com o comprometimento dos empregados, com o espírito de classe e com o desempenho empresarial. Finalmente, adotamos também a hipótese de que a ligação entre a orientação para o mercado e o desempenho empresarial é moderada pela turbulência do mercado, pela intensidade competitiva e pela turbulência tecnológica. Como há em Kohli e Jaworski (1990) uma discussão bastante profunda dessas hipóteses, fornecemos aqui apenas uma breve síntese delas para reservar espaço para a discussão detalhada dos aspectos empíricos da pesquisa.

Figura 1 - Antecedentes e conseqüências da orientação para 0 mercado.

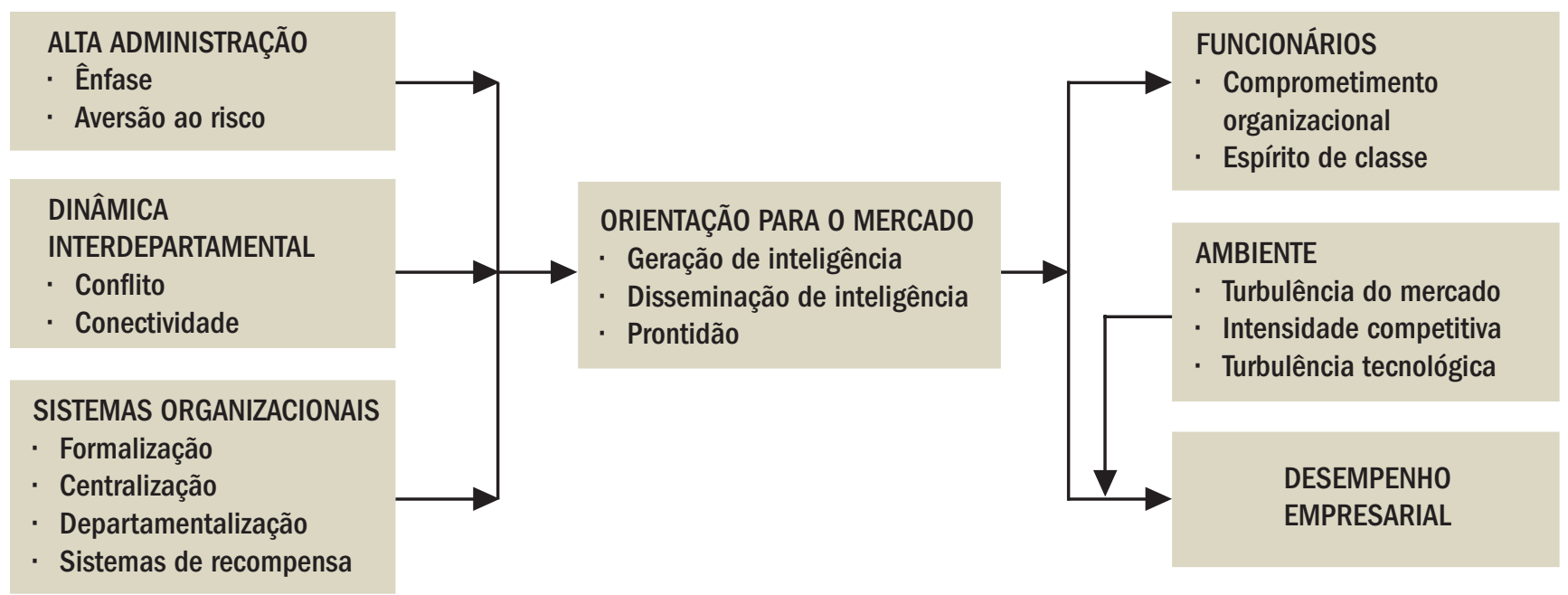




\section{Antecedentes da orientação para 0 mercado}

$\mathrm{O}$ primeiro conjunto de antecedentes incluído neste estudo se refere à alta administração de uma organização. Diversos autores sugerem que os altos administradores representam um papel fundamental, moldando os valores e a orientação das organizações (veja, por exemplo, Felton, 1959; Hambrick e Mason, 1984; Webster, 1988). O tema central dessas obras é que, a menos que uma organização receba sinais claros da alta administração quanto à importância de responder às necessidades do cliente, é improvável que ela se volte para o mercado (veja Levitt 1969; Webster 1988, p. 37). O reforço, pela alta administração, da importância da orientação para o mercado tende a incentivar os membros da organização a acompanhar as mudanças do mercado, a compartilhar a inteligência de mercado com outros membros e a ter capacidade de resposta às necessidades do mercado. Assim:

$\mathrm{H}_{1}$ : Quanto maior a ênfase dada pela alta administração a uma orientação para o mercado, maior (1) a geração de inteligência de mercado, (2) a disseminação da inteligência e (3) a prontidão da organização.

Um segundo antecedente da orientação para o mercado tem a ver com a postura dos altos administradores frente ao risco. Reagir às mudanças dos mercados muitas vezes exige a introdução de novos produtos e serviços para atender às necessidades e expectativas dos clientes. Mas novos produtos, serviços e programas muitas vezes apresentam risco de fracasso e tendem a ser mais evidentes do que produtos estabelecidos. Kohli e Jaworski (1990) propõem que, se a alta administração demonstrar disposição para assumir os riscos e aceitar eventuais fracassos como algo natural, será mais provável que os administradores menos graduados proponham e introduzam novas ofertas em resposta às mudanças das necessidades dos clientes. Por outro lado, se a alta administração for avessa ao risco e intolerante em relação a fracassos, será menos provável que seus subordinados se concentrem em gerar ou disseminar inteligência de mercado ou em reagir a mudanças das necessidades dos clientes. Assim, é de se esperar que,

$\mathrm{H}_{2}$ : Quanto maior a aversão da alta administração ao risco, menor (1) a geração de inteligência de mercado, (2) a disseminação de inteligência e (3) a prontidão da organização.

O segundo conjunto de fatores que pela hipótese tem efeito sobre a orientação para o mercado é a dinâmica interdepartamental. Um fator especialmente evidente que se presume afetar a orientação para o mercado é o conflito interdepartamental, referente à tensão entre os departamentos que decorre da incompatibilidade de reações reais ou desejadas (Gaski, 1984; Raven e Kruglanski, 1970, p. 70). Diversos autores apontam o conflito interdepartamental como inibidor da orientação para o mercado (veja Levitt, 1969; Lusch, Udell e Laczniak, 1976; Felton, 1959). Essencialmente, o conflito interdepartamental tende a inibir a comunicação entre os departamentos (Ruekert e Walker, 1987), reduzindo, assim, a disseminação da inteligência de mercado. Além disso, a tensão entre os departamentos provavelmente inibirá uma resposta coordenada deles às necessidades do mercado, prejudicando, assim, a orientação para o mercado. Não é de se esperar que haja efeitos sobre a geração de inteligência, uma vez que o conflito interdepartamental não deve afetar o processo de aquisição de informações de cada departamento individualmente. Assim,

$\mathrm{H}_{3}$ : Quanto maior o conflito interdepartamental, menor (1) a disseminação de inteligência de mercado e (2) a prontidão da organização.

Também se presume que a orientação para o mercado seja afetada pelo grau de conectividade interdepartamental, que se refere ao grau de contato direto formal e informal entre os funcionários dos diferentes departamentos. Diversas linhas correlatas de pesquisa sugerem que tal ligação facilita a interação e o intercâmbio de informações (veja Cronbach e associados, 1981; Deshpande e Zaltman, 1982; Patton, 1978). Assim, é de se esperar que, quanto maior a conectividade direta (ou formação de redes) entre os membros dos diferentes departamentos, mais probabilidade haverá que eles troquem entre si inteligência de mercado e reajam de forma coordenada (veja também Kohli e Jaworski, 1990). Como no caso anterior, nenhum efeito é esperado sobre o componente "geração de inteligência". Assim,

\footnotetext{
$\mathrm{H}_{4}$ : Quanto maior a conectividade interdepartamental, maior (1) a disseminação da inteligência de mercado e (2) a prontidão da organização.
}

O terceiro conjunto de antecedentes que presumivelmente afeta a orientação para o mercado se refere à estrutura e aos sistemas operacionais. Três variáveis estruturais - formalização, centralização e departamen- 
talização - devem ser consideradas em primeiro lugar. A formalização representa o grau a que chegam as regras que definem papéis, relações com a autoridade, comunicação, normas e sanções e procedimentos (Hall, Haas e Johnson, 1967). A centralização é o inverso do montante de delegação de autoridade decisória numa organização e a medida da participação dos membros da organização na tomada de decisões (Aiken e Hage, 1968). A departamentalização refere-se ao número de departamentos em que as atividades organizacionais são segregadas e compartimentadas.

As pesquisas existentes até o momento sugerem que tanto a formalização quanto a centralização estão inversamente relacionadas com a utilização da informação (veja Deshpande e Zaltman, 1982; Hage e Aiken, 1970; Zaltman, Duncan e Holbek, 1973). No contexto deste estudo, a utilização da informação corresponde à elaboração de programas em resposta à inteligência de mercado. Assim, como propõe Stampfl (1978), parece que a formalização e a centralização estão inversamente relacionadas com a capacidade de prontidão das organizações. No mesmo sentido, Lundstrom (1976) e Levitt (1969) discutem a departamentalização como barreira à comunicação e à disseminação da inteligência de mercado.

É interessante observar que não há motivos para crer que a estrutura organizacional não possa afetar os três componentes da orientação para o mercado da mesma maneira. Como observamos anteriormente, já que a orientação para o mercado requer que se faça algo novo ou diferente em resposta às condições do mercado, ela pode ser encarada como uma forma de comportamento inovador. Zaltman, Duncan e Holbek (1973, p. 62) caracterizam o comportamento inovador como sendo composto de dois estágios: (1) o estágio de iniciação, ou seja, conscientização e tomada de decisão, e (2) o estágio de implementação, ou seja, a execução da decisão tomada. Nesse contexto, o estágio de iniciação corresponde à geração e disseminação de inteligência e à concepção da resposta organizacional, ao passo que o estágio de implementação corresponde à resposta propriamente dita dada pela organização.

Zaltman, Duncan e Holbek (1973) baseiam-se em numerosos estudos para argumentar que dimensões organizacionais como formalização, centralização e departamentalização podem ter efeitos opostos sobre os dois estágios do comportamento inovador. Mais especificamente indicam que, embora essas variáveis possam afetar negativamente o estágio de iniciação do comportamento inovador, também podem facilitar o estágio de implementação. Isso sugere que a formalização, a centralização e a departamentalização podem se relacionar inversamente com a geração e disseminação da inteligência de mercado e com a concepção da resposta, mas relacionar-se diretamente com a implementação dessa resposta. Assim, lançamos as hipóteses:

$\mathrm{H}_{5}$ : Quanto maior a formalização, (1) menores a geração e disseminação de inteligência e a concepção de resposta, e (2) maior a implementação da resposta. $\mathrm{H}_{6}$ : Quanto maior a centralização, (1) menores a geração e disseminação de inteligência e a concepção de resposta, e (2) maior a implementação da resposta.

$\mathrm{H}_{7}$ : Quanto maior a departamentalização, (1) menores a geração e disseminação de inteligência e a concepção de resposta, e (2) maior a implementação da resposta.

O último antecedente investigado neste estudo se relaciona com o sistema de mensuração e recompensas vigente numa organização. A literatura sobre o tema sugere que os sistemas de mensuração/recompensa são fundamentais na formação do comportamento dos empregados (Anderson e Chambers, 1985; Jaworski, 1988; Lawler e Rhode, 1976; Hopwood, 1974). Neste contexto, Webster (1988, p. 38) argumenta que “... a chave para o desenvolvimento de um negócio movido pelo mercado e voltado para o cliente está na maneira como os administradores são avaliados e recompensados". Ele observa que, se os administradores forem avaliados principalmente com base na lucratividade e nas vendas no curto prazo, provavelmente se concentrarão nesses critérios, negligenciando fatores de mercado, como a satisfação do cliente, que asseguram a saúde de uma organização a longo prazo. Nos termos desses argumentos, é de se esperar que os membros de organizações que enfatizam a satisfação do cliente e o comportamento voltado para o mercado como bases da oferta de recompensas venham a gerar mais prontamente inteligência de mercado, disseminá-la internamente e ser sensíveis às necessidades do mercado. Ou seja

$\mathrm{H}_{8}$ : Quanto maior o emprego de fatores baseados no mercado para avaliar e recompensar os administradores, maiores (1) a geração de inteligência de mercado, (2) a disseminação da inteligência de mercado e (2) a capacidade de resposta da organização.

\section{Conseqüências da orientação para 0 mercado}

Freqüentemente se sugere que uma orientação para o mercado melhora o desempenho empresarial. O argu- 
mento é que as organizações voltadas para o mercado, ou seja, aquelas que acompanham as necessidades e preferências dos clientes e reagem a elas, podem melhor satisfazer seus clientes e, portanto, apresentam melhor desempenho. O estudo de Lusch e Laczniak (1987) dá sustentação a essa relação. Outro estudo mais recente de Narver e Slater (1990) também oferece apoio empírico à relação proposta entre orientação para o mercado e desempenho empresarial. A hipótese formal a testar é:

$\mathrm{H}_{9}$ : Quanto mais orientada para o mercado for uma organização, melhor será seu desempenho empresarial.

O conjunto de conseqüências examinado a seguir neste estudo se concentra nos empregados da organização. A pesquisa relatada por Kohli e Jaworski (1990) sugere que uma orientação para o mercado propicia diversos benefícios psicológicos e sociais aos empregados. Mais especificamente, afirma-se que uma orientação para o mercado leva a um sentimento de orgulho de pertencer a uma organização em que todos os departamentos e todas as pessoas trabalham para atingir a meta comum de satisfazer à clientela. Presume-se que a realização desse objetivo resulte no compartilhamento, pelos empregados, de um sentido de pertinência e, portanto, de comprometimento com a organização. A hipótese formal a testar é:

$\mathrm{H}_{10}$ : Quanto maior a orientação para o mercado, maiores o (1) espírito de classe e o (2) comprometimento organizacional dos empregados.

Como observamos anteriormente, diversos estudiosos sugerem que o contexto ambiental de uma organização tende a influenciar seu nível de orientação para o mercado. Com isso, pode-se esperar que organizações inseridas em ambientes mais competitivos sejam mais voltadas para o mercado (Lusch e Laczniak, 1987). Diversos estudiosos partem desse argumento genérico para sugerir que a importância da orientação para o mercado varia de acordo com o contexto ambiental (veja Bennett e Cooper, 1981; Houston 1986; Tauber 1974). Noutras palavras, afirmam que o elo entre orientação para o mercado e desempenho depende das características ambientais da organização.

Constam deste estudo três características ambientais que, segundo propõem Kohli e Jaworski (1990), influenciam o elo entre a orientação para o mercado e o desempenho. Primeiro, considera-se a turbulência do mercado, isto é, a taxa de variação da composição dos clientes e de suas preferências. Organizações que operam em mercados mais turbulentos tendem a precisar modificar constantemente seus produtos e serviços para atender continuamente às preferências de seus clientes. Por outro lado, os produtos e serviços de uma organização provavelmente precisarão de relativamente pouca modificação em mercados estáveis onde as preferências dos clientes não mudem muito. Assim sendo, as empresas que operam nos mercados mais turbulentos provavelmente têm maior necessidade de ser orientadas para o mercado, ou seja, de acompanhar as mudanças das preferências dos clientes e reagir a elas, do que as empresas de mercados mais estáveis. Em outras palavras, a orientação para o mercado tende a ser mais fortemente relacionada com o desempenho em mercados turbulentos do que em mercados estáveis. Formalmente:

$\mathrm{H}_{11}$ : Quanto maior a turbulência do mercado, mais forte a relação entre a orientação para o mercado e o desempenho empresarial.

Um segundo fator ambiental que pode ser apontado como moderador entre a orientação para o mercado e o desempenho empresarial é a intensidade da competição. Como observam Houston (1986) e Kohli e Jaworski (1990), na falta de competição uma organização pode ter bom desempenho mesmo que não seja muito orientada para o mercado, uma vez que os clientes estão "presos" aos produtos e serviços da organização em questão. Por outro lado, sob condições de competição acirrada, os clientes podem contar com opções alternativas para satisfazer às suas necessidades e desejos. Com isso, uma organização não muito orientada para o mercado tende a perder clientes para a competição e ter fraco desempenho, portanto é de se esperar que a orientação para o mercado seja uma determinante de desempenho mais importante em condições de maior intensidade competitiva. Ou seja:

$\mathrm{H}_{12}$ : Quanto maior a intensidade competitiva, mais forte a relação entre a orientação para o mercado e o desempenho empresarial.

O terceiro fator ambiental que se propõe como moderador da relação entre a orientação para o mercado e o desempenho empresarial é a turbulência tecnológica definida como a taxa de mudança da tecnologia. A orientação para o mercado é essencialmente um meio de de- 
senvolver vantagem competitiva, uma vez que permite à organização entender as necessidades dos clientes e oferecer produtos e serviços para atender a essas necessidades. Embora isso seja importante, pode haver caminhos alternativos para a obtenção de vantagem competitiva. Um deles é a tecnologia. Organizações que trabalham com tecnologias nascentes e sujeitas a mudanças aceleradas podem ser capazes de obter uma vantagem competitiva por meio da inovação tecnológica, reduzindo assim, mas não eliminando, a importância da orientação para o mercado. Por outro lado, organizações que trabalham com tecnologias estáveis (maduras) situam-se numa posição relativamente fraca para alavancar a tecnologia e com isso obter vantagem competitiva, dependendo mais da orientação para o mercado. Para mais argumentos nesse sentido, veja Bennett e Cooper (1981), Houston (1986), Kaldor (1971) e Tauber (1974). A discussão acima sugere que:

$\mathrm{H}_{13}$ : Quanto maior a turbulência tecnológica, mais fraca a relação entre a orientação para o mercado e o desempenho empresarial.

\section{COLETA DE DADOS}

\section{Amostra I}

A primeira amostra foi retirada das empresas membros do Marketing Science Institute (MSI) e das 1.000 maiores empresas por faturamento do Million Dollar Directory da Dun \& Bradstreet. Foi empregada na amostra uma concepção de múltiplos informantes.

Enviou-se uma carta do presidente da MSI a um executivo graduado de cada uma das 49 empresas membro do Instituto, solicitando sua participação no estudo. Pediu-se a cada executivo que fornecesse os nomes de um executivo graduado de marketing e de um executivo graduado não ligado a marketing em uma ou mais Unidades de Negócio (UNs) da empresa para posterior contato dos pesquisadores. Do total de 49 empresas, 13 concordaram em participar do estudo e forneceram os nomes de pessoas em 27 UNs. Para cada UN foram fornecidos os nomes de um executivo de marketing e outro de área não relacionada a marketing. A cada um dos dois informantes em cada UN enviou-se uma cópia do questionário, acompanhada de uma carta personalizada e de um envelope para resposta. Enviou-se também a cada pessoa um cartãopostal, como lembrete, aproximadamente uma sema- na após a primeira postagem. Depois de três semanas, enviou-se a cada informante uma cópia adicional do questionário, acompanhada de carta personalizada. A taxa de respostas foi de $88,9 \%$ entre os executivos de marketing e de $77,8 \%$ entre os demais executivos.

Da amostra da Dun \& Bradstreet foram retiradas 500 empresas dentre as 1.000 maiores, selecionandose item sim, item não. O contato inicial se deu com o CEO de cada empresa por meio de carta personalizada solicitando participação da empresa no estudo. Vinte e uma empresas não puderam ser contatadas por causa de endereços incorretos e sucessões de CEOs, o que resultou numa base efetiva de 479 empresas. Pediu-se aos CEOs que indicassem os nomes de dois executivos (um de marketing, outro não) em suas UNs para que agissem como informantes. Um total de $102 \mathrm{em}-$ presas concordou em participar, e obtiveram-se os 229 nomes em UNs. Foram dados os nomes de 206 executivos de marketing e 187 executivos de outras áreas. Os informantes dessas UNs foram então contatados diretamente pelos pesquisadores, que lhes pediram que preenchessem e devolvessem o questionário de estudo de acordo com o procedimento descrito para as empresas do MSI. A taxa de respostas foi de $79,6 \%$ entre os executivos de marketing e de $70 \%$ entre os outros.

Esses procedimentos resultaram em respostas de um total de 222 unidades de negócio. O market share dessas unidades variava entre $1 \%$ e $100 \%$, com share médio de $30 \%$. Para fins de análise, obteve-se a média das respostas dos dois informantes para se chegar à pontuação de cada unidade de negócio. Nos relativamente poucos casos em que apenas um informante forneceu os dados, as respostas foram usadas em sua forma original.

\section{Amostra II}

Para se proceder à validação cruzada das conclusões da amostra acima, obtiveram-se dados de uma segunda amostra. A base de amostragem nesse caso foi a lista de membros da American Marketing Association, que forneceu os nomes de mais informantes. Partindo dessa amostra, foram selecionados aleatoriamente 500 nomes após se eliminarem aqueles cujos títulos sugeriam posição hierárquica relativamente baixa. Desses 500 nomes, 13 não puderam ser contatados por causa de endereços incorretos, o que resultou numa base efetiva de 487. Utilizou-se o procedimento postal em três ondas acima descrito para se obterem os dados desta amostra. Obteve-se um total de 230 respostas, com uma taxa de respostas de $47,2 \%$. 


\section{DESENVOLVIMENTO E REFINAMENTO DO INSTRUMENTO}

O estudo usou escalas existentes para medir os construtos de estrutura organizacional de formalização, centralização e departamentalização. Não constavam na literatura escalas para os demais construtos incluídos no estudo. Assim, o primeiro passo foi o desenvolvimento de novas escalas para esses construtos. Para tanto adotou-se o procedimento iterativo em quatro fases descrito a seguir.

Primeiro, os autores geraram independentemente um grande conjunto de itens para cada um dos construtos constantes do estudo. Tomou-se o cuidado de explorar ao máximo o domínio de cada construto. Por exemplo, foram gerados diversos itens correspondentes a cada um dos componentes da orientação para o mercado. Desse conjunto de itens, selecionou-se um subconjunto por meio dos critérios de unicidade e capacidade de transmitir "diferentes nuances de significado" (veja Churchill, 1979). Em diversos itens se aplicou pontuação reversa para minimizar o viés do conjunto de respostas.

A seguir, por causa da centralidade da escala de orientação para o mercado, seus itens foram testados em termos de clareza e adequação, em pré-testes aplicados pessoalmente a 27 administradores dos departamentos de marketing e de não marketing e dos níveis administrativos mais elevados. Pediu-se aos administradores que preenchessem um questionário do qual constavam os itens e indicassem quaisquer ambigüidades ou outras dificuldades encontradas, e que oferecessem quaisquer outras sugestões que considerassem apropriadas. Com base no feedback recebido dos administradores, alguns itens foram eliminados, outros foram modificados e ainda novos itens foram desenvolvidos.

Seguiu-se uma nova fase de pré-testes em que as escalas de todos os construtos foram identificadas como tal e apresentadas a sete peritos acadêmicos a quem pedimos que avaliassem criticamente os itens dos pontos de vista da representatividade do domínio, da especificidade do item e da clareza de construção. Com base na crítica detalhada assim obtida, alguns itens foram eliminados e outros foram revistos para aprimorar sua especificidade e precisão.

Os itens desenvolvidos e refinados foram submetidos ainda a outra fase de pré-testes que envolveu entrevistas pessoais com sete administradores a quem pedimos que preenchessem um questionário que incluía os itens de mensuração tal como aplicados a suas unidades de negócio. Nesse estágio foram levantados muito poucos ques- tionamentos e realizados refinamentos de extrema sutileza. Segue-se uma breve descrição dos itens finais da escala. As escalas completas constam do Apêndice.

A orientação para o mercado foi medida numa escala de 32 itens. Desses, 10 referem-se à geração de inteligência de mercado, oito à disseminação da inteligência e 14 à capacidade de resposta no nível da unidade de negócio. Dos 14 itens sobre prontidão, sete exploram como a organização desenvolve planos em reação à inteligência de mercado (concepção de resposta) e os outros sete avaliam a efetiva implementação desses planos (implementação de resposta). Nos termos de Lusch e Laczniak (1987), os itens que exploravam os três componentes foram entremeados com questões relacionadas às necessidades e preferências de clientes e usuários finais, atos da competição e tendências reguladoras. Exemplos de itens para os três componentes são: (1) "Em nossa unidade de negócio, a inteligência sobre os concorrentes é gerada independentemente por diversos departamentos", (2) "Realizamos reuniões interdepartamentais pelo menos a cada trimestre para discutir tendências e desdobramentos do mercado", e (3) "As reclamações dos clientes não são ouvidas nesta unidade de negócio" (pontuação reversa). Cada item foi avaliado numa escala de 5 pontos que ia de "discordo fortemente" a "concordo fortemente".

A ênfase dada pela alta administração à orientação para o mercado e à aversão ao risco foi medida em duas escalas separadas. A primeira se compunha de quatro itens (como "Os administradores graduados dizem reiteradamente aos empregados que a sobrevivência da unidade de negócio depende de sua adaptação às necessidades do mercado"). Os itens dessa escala se concentraram no reforço verbal fornecido pela alta administração a atividades orientadas para o mercado. A escala de aversão ao risco se compunha de seis itens (por exemplo, "Os altos administradores desta unidade de negócio gostam de jogar seguro"), e foram avaliadas suas disposições para tomar medidas inovadoras em situações de risco e incerteza. Os itens de cada uma das duas escalas foram avaliados numa escala de 5 pontos que ia de "discordo fortemente" a "concordo fortemente".

Os dois construtos referentes à dinâmica interdepartamental - conflito e grau de conectividade - foram medidos em escalas de sete itens. Os itens de conflito se referiam à medida da incompatibilidade entre as metas de diferentes departamentos e à tensão existente nas interações interdepartamentais (por exemplo, "proteger o próprio território é parte do modo de vida dessa unidade de negócio"). Os itens de conectividade explo- 
ravam o quanto as pessoas de um determinado departamento estavam ligadas aos diversos níveis hierárquicos de outros departamentos. Por exemplo, "Nesta unidade de negócio é fácil conversar com qualquer pessoa, independentemente da graduação ou do cargo". Os itens de cada escala receberam de 1 a 5 pontos, indo de "discordo fortemente" a "concordo fortemente".

A formalização e a centralização foram medidas segundo as escalas largamente utilizadas desenvolvidas por Aiken e Hage $(1966,1968)$. A escala de formalização, de nove itens, avaliava a medida da codificação dos cargos na empresa, e se havia ou não ênfase na observação de regras. Por exemplo, "A maneira como as coisas são feitas aqui depende de quem está fazendo" (pontuação reversa). A escala de centralização, de cinco itens, avaliava o grau de autoridade hierárquica da organização. Por exemplo, "Alguém que queira decidir aqui será rapidamente desencorajado". Todos os itens foram avaliados numa escala de 5 pontos que ia de "discordo fortemente" a "concordo fortemente".

A departamentalização foi medida por meio de uma contagem do número de departamentos da unidade de negócio. A orientação do sistema de recompensas foi medida numa escala de seis itens que avaliava em que medida as relações com o cliente, a satisfação do cliente e comportamentos orientados para o mercado eram usados para avaliar e recompensar os membros da organização. Por exemplo, "As avaliações de satisfação do cliente influenciam o pagamento dos altos administradores nesta unidade de negócio". Para esses itens, foi utilizado um formato de avaliação em 5 pontos ( 1 = discordo fortemente; 5 = concordo fortemente).

A turbulência do mercado, a intensidade competitiva e a turbulência tecnológica foram medidas por três escalas, compostas respectivamente de seis, seis e cinco itens. Os itens quanto à turbulência do mercado avaliavam em que medida a composição e as preferências dos clientes de uma organização tendiam a mudar com o tempo. Por exemplo, "Estamos percebendo demanda para nossos produtos e serviços entre clientes que jamais os compraram antes". Os itens de intensidade competitiva avaliavam o comportamento, os recursos e a capacidade de diferenciação dos concorrentes. Por exemplo, "Qualquer coisa que um competidor ofereça pode ser prontamente replicada pelos demais". A turbulência tecnológica explorava a mutabilidade da tecnologia de um setor. Por exemplo, "A tecnologia de nosso setor está mudando com rapidez". Foi usado para todos os itens um formato de avaliação em 5 pontos ( 1 $=$ discordo fortemente $5=$ concordo fortemente).
O desempenho empresarial foi medido por meio de duas abordagens diferentes encontradas na literatura usando tanto medidas subjetivas como objetivas. A medida subjetiva pedia aos informantes que avaliassem o desempenho geral da empresa e seu desempenho relativo em relação aos principais concorrentes numa escala de 5 pontos que ia de "fraco" a "excelente". A medida objetiva era a parcela de mercado expressa em dólares.

O comprometimento organizacional e o espírito de classe foram medidos por meio de duas escalas de sete itens. Os itens da escala de comprometimento organizacional exploravam o quanto os empregados gostavam da organização empregadora, até que ponto consideravam seu futuro atrelado ao dela e estavam dispostos a fazer sacrifícios pessoais pela unidade de negócio. Por exemplo, "Os empregados freqüentemente vão acima e além do dever para garantir o bem-estar desta unidade de negócio". A escala de espírito de classe avaliava a prevalência do senso de equipe na organização. Por exemplo, "Todas as pessoas desta unidade de negócio estão realmente preocupadas com as necessidades e problemas de todas as demais". Todos os itens foram avaliados numa escala de 5 pontos que ia de "discordo fortemente" a "concordo fortemente".

Todas as escalas acima foram refinadas da maneira descrita a seguir. A confiabilidade de cada uma foi estimada por meio do cômputo de seu coeficiente alfa. Itens com baixas correlações com os demais foram eliminados para melhorar a consistência interna das escalas. O coeficiente de confiabilidade de cada escala consta do Apêndice (salvo pelo construto de capacidade geral de resposta, cujo coeficiente de confiabilidade foi 0,89 ). Como se pode ver no Apêndice, as escalas refinadas apresentam, de maneira geral, coeficientes de confiabilidade de bons a elevados, superando os níveis recomendados por Nunnally (1978).

\section{ANÁLISES E RESULTADOS}

Os dados obtidos da Amostra 1 foram analisados para avaliar o grau de congruência entre os dois informantes. Primeiramente, foi calculada a diferença entre as pontuações atribuídas pelos informantes a cada um dos 26 construtos do estudo. As diferenças absolutas médias para 21 dos 26 construtos foi inferior a 1,0. Em cinco construtos as diferenças médias variaram entre 1,01 e 3,86. Dado que a maioria das escalas inclui diversos itens, cada um classificado numa escala de 5 
pontos, as diferenças observadas foram muito pequenas, da ordem de $5 \%$ ou menos, e pareceram indicar falta de viés sistemático numa direção ou noutra entre os relatos dos gestores de marketing e não marketing.

Em segundo lugar, para cada um dos construtos, foi computada a correlação entre as respostas dos executivos de marketing e não marketing. De modo geral, as correlações foram moderadas e positivas $(0,09,0,17$, $0,35,0,28,0,39,0,29,0,24,-0,07,0,31,0,36,0,52$, $0,84,0,02,0,29,0,17,0,24,0,18,0,26,0,42,0,53,0,37$, $0,33,0,51,0,17,0,33,0,34)$. Embora os dois relatos estejam positivamente correlacionados, as correlações não são perfeitas, o que sugere que os dois informantes estejam adotando diferentes perspectivas ao fornecerem suas respostas (a ausência de congruência perfeita entre os informantes foi totalmente condizente com estudos anteriores com múltiplos informantes [por exemplo, Silk e Kalwani, 1982] constantes da literatura). Assim, extraímos a média das pontuações atribuídas pelos dois informantes para chegar à pontuação de cada construto, numa tentativa de obter uma medida mais completa das características focais da organização.

Em seguida, as pontuações de orientação para o mercado e outros construtos com múltiplos itens foram calculadas por meio da ponderação e do somatório das pontuações dos itens correspondentes. Com isso, a pontuação de orientação para o mercado passou a ser o somatório não ponderado dos três componentes, geração, disseminação e prontidão. A pontuação média de orientação para o mercado foi de 113,95 , com desvio padrão de 15,80 e amplitude de 68,5 a 150, de uma amplitude possível de 31 a 155. A correlação entre os componentes geração e disseminação foi de 0,62 ; entre disseminação e prontidão foi de 0,70 ; e entre prontidão e geração foi de 0,55 . Ademais as correlações entre a orientação para o mercado geral e os componentes geração, disseminação e prontidão foram de $0,79,0,88$ e 0,92 , respectivamente.

As primeiras nove hipóteses $\left(\mathrm{H}_{1}\right.$ a $\left.\mathrm{H}_{9}\right)$ estão relacionadas aos antecedentes da orientação para o mercado e foram testadas por meio da estimativa das seguintes equações de regressão:

$$
\begin{aligned}
& Y_{1}=b_{1} X_{1}+b_{2} X_{2}+\ldots+b_{8} X_{8}+e_{1} \\
& Y_{2}=b_{1} X_{1}+b_{2} X_{2}+\ldots+b_{8} X_{8}+e_{2} \\
& Y_{3}=b_{1} X_{1}+b_{2} X_{2}+\ldots+b_{8} X_{8}+e_{3} \\
& Y_{4}=b_{1} X_{1}+b_{2} X_{2}+\ldots+b_{8} X_{8}+e_{4}
\end{aligned}
$$

onde $Y_{1}$ representa a orientação para o mercado geral, $Y_{2}$ a $Y_{4}$ representam respectivamente geração de inteli- gência de mercado, disseminação de inteligência de mercado e prontidão, e $X_{1}$ a $X_{8}$ correspondem a (1) ênfase da alta administração sobre orientação para o mercado, (2) aversão da alta administração ao risco, (3) conflito interdepartamental, (4) conectividade interdepartamental, (5) formalização, (6) centralização, (7) departamentalização e (8) orientação do sistema de recompensas. Como, pelas nossas hipóteses, o conflito interdepartamental e a conectividade interdepartamental afetam a disseminação da inteligência e a prontidão mas não a geração da inteligência $\left(\mathrm{H}_{3}, \mathrm{H}_{4}\right)$, conflito e conectividade não foram incluídos como preditores da geração de inteligência na segunda equação acima. Os resultados obtidos com a estimativa das quatro equações a partir das Amostras I e II constam das Tabelas 1 e 2.

Além disso, as hipóteses de $\mathrm{H}_{5}$ a $\mathrm{H}_{7}$ referem-se aos efeitos opostos da formalização, centralização e departamentalização sobre os dois componentes da prontidão - concepção da resposta e implementação da resposta. Assim sendo, foram estimadas mais duas equações de regressão, por meio da incorporação da concepção de resposta e da implementação de resposta como variáveis dependentes e das oito variáveis independentes anteriormente referidas. O resultado obtido para os efeitos da formalização, centralização e departamentalização sobre os dois componentes da prontidão, nas duas amostras, foi idêntico ao obtido para a capacidade geral de resposta, como consta das Tabelas 1 e 2 .

As Hipóteses 9 e 10 se referiam ao efeito da orientação para o mercado sobre o desempenho empresarial e o comprometimento dos empregados com a organização e seu espírito de classe. Essas hipóteses foram testadas por meio da regressão do desempenho, usando tanto a medida subjetiva quanto a objetiva baseada em market share, com relação à orientação para o mercado. Para controlar os efeitos de outras determinantes do desempenho, foram incorporadas nas equações de regressão seis variáveis de controle como variáveis independentes. As variáveis de controle referiam-se a intensidade competitiva, poder do comprador, poder do fornecedor, barreiras à entrada, pressão de produtos substitutos e qualidade do produto. A literatura sugere que essas variáveis sejam determinantes importantes do desempenho (por exemplo, Boulding e Staelin, 1990; Jacobson e Aaker, 1987; Porter, 1980). Foram desenvolvidas medidas dessas variáveis especialmente para este estudo. Da mesma forma, o comprometimento organizacional e o espírito de classe dos 
empregados foram regredidos separadamente em relação à orientação para o mercado e às variáveis de controle para testar $\mathrm{H}_{9}$ e $\mathrm{H}_{10}$. Os resultados obtidos constam das Tabelas 3 e 4.

Finalmente, $\mathrm{H}_{11}$ a $\mathrm{H}_{13}$ lançam as hipóteses de que o impacto de uma orientação para o mercado dependeria do nível da turbulência do mercado, da intensidade competitiva e da turbulência tecnológica. Para testar o efeito moderador das três variáveis moderado- ras, realizou-se uma análise separada com a Amostra I e a Amostra II (veja Arnold, 1982). Primeiramente, a amostra foi organizada por ordem crescente de uma variável moderadora, turbulência do mercado, por exemplo, e então dividida na altura da mediana para formar dois grupos, um com turbulência do mercado relativamente baixa e outro com turbulência do mercado relativamente elevada. Em seguida, fez-se uma regressão com o desempenho em relação à orientação

Tabela 1 - Antecedentes da orientação para o mercado: coeficientes de regressão padronizados estimados com a Amostra I.

\begin{tabular}{|c|c|c|c|c|}
\hline & \multicolumn{4}{|c|}{ VARIÁVEIS DEPENDENTES } \\
\hline $\begin{array}{c}\text { VARIÁVEIS } \\
\text { INDEPENDENTES }\end{array}$ & $\begin{array}{c}\text { ORIENTAÇÃO PARA } \\
\text { O MERCADO }\end{array}$ & $\begin{array}{l}\text { GERAÇÃO DE } \\
\text { INTELIGÊNCIA }\end{array}$ & $\begin{array}{l}\text { DISSEMINAÇÃO DE } \\
\text { INTELIGÊNCIA }\end{array}$ & PRONTIDÃO \\
\hline Ênfase da alta administração & $0,24 * *$ & $0,27^{* * *}$ & $0,25^{* * *}$ & $0,20 * *$ \\
\hline Aversão ao risco da alta administração & Ns & Ns & Ns & $-0,24 * * *$ \\
\hline Conflito interdepartamental & $-0,17^{*}$ & - & $-0,27 * * *$ & $-0,23^{* *}$ \\
\hline Conectividade interdepartamental & $0,20 * *$ & - & Ns & Ns \\
\hline Formalização & Ns & Ns & Ns & Ns \\
\hline Centralização & $-0,22 * *$ & Ns & $-0,14^{*}$ & $-0,22 * *$ \\
\hline Departamentalização & Ns & Ns & Ns & Ns \\
\hline Orientação do sistema de recompensas & $0,30 * * *$ & $0,39 * * *$ & $0,24 * * *$ & $0,16 *$ \\
\hline $\mathrm{R}^{2}$ & 0,63 & 0,34 & 0,49 & 0,54 \\
\hline $\mathrm{N}$ & 134 & 144 & 154 & 150 \\
\hline
\end{tabular}

Tabela 2 - Antecedentes da orientação para o mercado: coeficientes de regressão padronizados estimados com a Amostra II.

\begin{tabular}{|c|c|c|c|c|}
\hline & \multicolumn{4}{|c|}{ VARIÁVEIS DEPENDENTES } \\
\hline $\begin{array}{c}\text { VARIÁVEIS } \\
\text { INDEPENDENTES }\end{array}$ & $\begin{array}{l}\text { ORIENTAÇÃO PARA } \\
\text { O MERCADO }\end{array}$ & $\begin{array}{l}\text { GERAÇÃO DE } \\
\text { INTELIGÊNCIA }\end{array}$ & $\begin{array}{l}\text { DISSEMINAÇÃO DE } \\
\text { INTELIGÊNCIA }\end{array}$ & PRONTIDÃO \\
\hline Ênfase da alta administração & $0,24 * *$ & $0,20 *$ & $0,28 * * *$ & $0,24 * * *$ \\
\hline Aversão ao risco da alta administração & Ns & Ns & Ns & $-0,12 *$ \\
\hline Conflito interdepartamental & $-0,28--$ & - & $-0,20 * * *$ & $-0,32 * * *$ \\
\hline Conectividade interdepartamental & $0,22 * *$ & - & 0,27 & Ns \\
\hline Formalização & Ns & Ns & Ns & Ns \\
\hline Centralização & Ns & $-0,34 * *$ & Ns & Ns \\
\hline Departamentalização & Ns & Ns & Ns & Ns \\
\hline Orientação do sistema de recompensas & $0,31 * * *$ & $0,38 * * *$ & $0,20 * *$ & $0,19 * *$ \\
\hline $\mathrm{R}^{2}$ & 0,58 & 0,33 & 0,38 & 0,55 \\
\hline $\mathrm{N}$ & 123 & 130 & 138 & 138 \\
\hline
\end{tabular}


para o mercado e as seis variáveis de controle da amostra completa, permitindo-se, ao mesmo tempo, que todos os coeficientes de regressão assumissem diferentes valores nos dois subgrupos.

Então, a equação de regressão foi novamente estimada, agora restringindo o coeficiente associado à orientação para o mercado para que assumisse o mesmo valor nos dois grupos. O teste Chow (1960) foi usado para avaliar a significância estatística da diferença entre os coeficientes de regressão da variável de orientação para o mercado dos subgrupos de baixa e alta turbulência do mercado. Os efeitos moderadores hipoté- ticos da intensidade competitiva e da turbulência tecnológica foram estimados da mesma maneira, reorganizando-se as amostras quanto a essas variáveis e procedendo-se da maneira descrita.

\section{ACHADOS E DISCUSSÃO}

Nesta seção, o enfoque está na interpretação substantiva dos resultados e dos achados que surgiram. Além disso, são discutidas diversas questões metodológicas associadas à interpretação dos resultados. Primeira-

Tabela 3 - Conseqüências de uma orientação para o mercado: coeficientes de regressão padronizados estimados com a Amostra I.

\begin{tabular}{|l|c|c|c|c|}
\hline \multicolumn{1}{|c|}{$\begin{array}{c}\text { VARIÁVEIS } \\
\text { INDEPENDENTES }\end{array}$} & $\begin{array}{c}\text { VESEMPENHO } \\
\text { GERAL }\end{array}$ & $\begin{array}{c}\text { MARKET } \\
\text { SHARE }\end{array}$ & $\begin{array}{c}\text { COMPROMETIMENTO } \\
\text { ORGANIZACIONAL }\end{array}$ & $\begin{array}{c}\text { ESPÍRITO } \\
\text { DE CLASSE }\end{array}$ \\
\hline Orientação para o mercado & $0,23^{* *}$ & Ns & $0,44^{* * *}$ & $0,51^{* * *}$ \\
\hline Qualidade do produto & $0,24^{* *}$ & Ns & $0,18^{*}$ & $0,18^{*}$ \\
\hline Intensidade competitiva & Ns & $-0,39 * *$ & Ns & Ns \\
\hline Poder dos compradores & Ns & Ns & Ns & Ns \\
\hline Poder dos fornecedores & Ns & $0,22^{*}$ & Ns & Ns \\
\hline Barreiras à entrada & Ns & Ns & Ns & Ns \\
\hline Substitutos & Ns & Ns & Ns & Ns \\
\hline$R^{2}$ & 0,18 & 0,06 & 0,31 & 0,40 \\
\hline$N$
\end{tabular}

$* * * p<0,001$

$* * p<0,01$

$* p<0,05$

Tabela 4 - Conseqüências de uma orientação para o mercado: coeficientes de regressão padronizados estimados com a Amostra II.

\begin{tabular}{|l|c|c|c|c|}
\hline \multicolumn{1}{|c|}{$\begin{array}{c}\text { VARIÁVEIS } \\
\text { INDEPENDENTES }\end{array}$} & $\begin{array}{c}\text { VESEMPENHO } \\
\text { GERAL }\end{array}$ & $\begin{array}{c}\text { MARKET } \\
\text { SHARE }\end{array}$ & $\begin{array}{c}\text { COMPROMETIMENTO } \\
\text { ORGANIZACIONAL }\end{array}$ & $\begin{array}{c}\text { ESPÍRITO } \\
\text { DE CLASSE }\end{array}$ \\
\hline Orientação para o mercado & $0,36 * * *$ & Ns & $0,66 * * *$ & $0,58^{* * *}$ \\
\hline Qualidade do produto & Ns & Ns & Ns & Ns \\
\hline Intensidade competitiva & Ns & $-0,21 *$ & Ns & Ns \\
\hline Poder dos compradores & Ns & Ns & Ns & Ns \\
\hline Poder dos fornecedores & Ns & Ns & Ns & Ns \\
\hline Barreiras à entrada & Ns & Ns & Ns & Ns \\
\hline Substitutos & Ns & Ns & Ns & Ns \\
\hline$R^{2}$ & 0,25 & 0,11 & 0,50 & 0,39 \\
\hline$N$ & 136 & 89 & 139 & 135 \\
\hline
\end{tabular}

*** $p<0,001$

$* * p<0,01$

$* p<0,05$ 
mente, focalizando os antecedentes de uma orientação para o mercado, há forte convergência entre as conclusões das duas amostras. As únicas exceções são os papéis da conectividade interdepartamental e da centralização organizacional (veja Tabelas 1 e 2). No geral, os resultados sugerem que diversos fatores moldam a orientação da organização para o mercado. A ênfase dada pela alta administração à orientação para o mercado parece afetar a geração de inteligência de mercado ( $b=0,27, p<0,001$, Amostra I; $b=0,20, p<$ 0,05 , Amostra II), sua disseminação pela organização $(b=0,25, p<0,001$, Amostra I; $b=0,28, p<0,001$, Amostra II) e a prontidão da organização $(b=0,20, p$ $<0,01$, Amostra I; $b=0,24, p<0,01$, Amostra II). Assim, parece importante que os altos administradores enfatizem constantemente, junto aos empregados, a necessidade de acompanhar os desdobramentos do mercado e de reagir a eles. A aversão dos altos administradores ao risco não parece afetar a geração ou a disseminação de inteligência, mas ter efeito negativo sobre a prontidão da organização $(b=-0,24, p<0,001$, Amostra I; $b=-0,12, p<0,05$, Amostra II). Essas conclusões dão sustentação à expectativa anteriormente existente de que reagir a desdobramentos do mercado envolve riscos e que se a alta administração não estiver disposta a enfrentá-los a organização tenderá a ter menor capacidade de resposta às mudanças das preferências dos clientes.

O conflito interdepartamental, como era esperado, parece inibir a disseminação de inteligência $(b=-0,27$, $p<0,001$, Amostra I; $b=-0,20, p<0,05$, Amostra II) e a prontidão da organização $(b=-0,23, p<0,01$, Amostra I; $b=-0,32, p<0,001$, Amostra II). Isso dá sustentação à expectativa de que os membros da organização em que haja tensão entre departamentos tenderiam a não compartilhar informações de mercado ou trabalhar coordenadamente com outros departamentos para atender às necessidades e expectativas da clientela.

Os resultados das duas amostras sugerem que a conectividade entre os departamentos promove a orientação para o mercado. Os resultados da Amostra II sugerem que a conectividade facilita a disseminação de inteligência na organização $(b=0,27, p<0,01)$, melhorando assim a orientação para o mercado. Curiosamente, na Amostra I a conectividade não parece estar relacionada com a disseminação de inteligência, muito embora esteja relacionada com a orientação geral para o mercado $(b=0,20, p<0,01)$. Esses resultados exigem mais pesquisa para examinar o elo entre conectividade e orientação para o mercado.
Voltando agora para o papel dos sistemas organizacionais, a orientação para o mercado parece estar muito fortemente relacionada aos sistemas de recompensa da organização $(b=0,30, p<0,001$, Amostra I; $b=0,31$, $p<0,001$, Amostra II). As organizações que recompensam seus empregados com base em fatores como satisfação do cliente, construção de relacionamentos com clientes e outras assemelhadas tendem a ser mais orientadas para o mercado.

A comparação dos coeficientes de regressão padronizados das Amostras I e II sugere que a concepção dos sistemas de recompensa tem máximo impacto sobre a orientação para o mercado dentre os componentes do conjunto incluído no estudo. Ter o sistema de recompensa "certo" parece facilitar os três componentes da orientação para o mercado - geração de inteligência $(b=0,39, p<0,001$, Amostra I, $b=0,38, p<$ 0,001 , Amostra II), disseminação da inteligência ( $b=$ $0,24, p<0,01$, Amostra I; $b=0,20, p<0,01$, Amostra II) e prontidão ( $b=16, p<0,05$, Amostra I; $b=0,19, p$ $<0,01$, Amostra II).

Os resultados das duas amostras sugerem que a centralização das decisões age como barreira à orientação para o mercado. Mas os padrões dos resultados dessa variável nas duas amostras são diferentes. Na Amostra I, a centralização é inversamente relacionada com a disseminação de inteligência $(b=-0,14, p<0,05)$ e a prontidão $(b=-0,22, p<0,01)$, enquanto na Amostra II a centralização é inversamente relacionada com a geração de inteligência $(b=-0,34, p<0,01)$.

Ao contrário das hipóteses anteriores, a formalização não parece se relacionar com a orientação para o mercado. Esse resultado corrobora, em parte, os relatados por Narver e Slater (1991), que sugerem que as abordagens programáticas à melhora da orientação para o mercado podem não ser eficazes. A formalização se refere à existência de regras e regulamentos formais numa organização e aos esforços da organização para fazer aplicar essas regras.

Comumente se argumenta que a ênfase nas regras faz com que a organização seja menos adaptável a mudanças externas. Embora os resultados sugiram que a formalização não esteja relacionada com a orientação para o mercado, uma interpretação alternativa é que a mera ênfase nas regras é menos relevante do que a natureza específica das regras vigentes numa organização. Noutras palavras, é possível que, se corretamente concebidas, as regras possam facilitar, e não dificultar, a orientação para o mercado. Por exemplo, uma organização pode usar as regras para determinar que 
os diversos departamentos se reúnam mensalmente para uma "avaliação do mercado". Tal regra provavelmente aumentaria a disseminação de inteligência. Da mesma forma, outras regras podem determinar resposta acelerada a reclamações de clientes ou outros acontecimentos no mercado, melhorando, assim, a orientação para o mercado. No mesmo sentido, a falta de relação entre departamentalização e orientação para o mercado sugere que o número de departamentos por si só seja menos importante do que a conectividade e o nível de conflito entre eles.

Quais são os efeitos da orientação para o mercado sobre o desempenho empresarial e sobre os empregados? Como mostram as Tabelas 3 e 4 , a orientação para o mercado parece estar significativamente relacionada com o desempenho empresarial quando se avalia o desempenho geral com base em medidas subjetivas $(b=$ $0,23, p<0,01$, Amostra I; $b=0,36, p<0,001$, Amostra II). Por outro lado, a orientação para o mercado não parece estar relacionada com o desempenho quando usamos a medida mais objetiva do market share. Esses resultados parecem dúbios no que tange à importância da orientação para o mercado. Mas, nesse contexto, há um número suficiente de questões dignas de nota.

Em primeiro lugar, não está claro se o market share seria um indicador particularmente apropriado de desempenho. Por exemplo, é possível que determinadas empresas de elevado desempenho possam seguir deliberadamente uma estratégia de "foco", não se preocupando com o market share (cf. Porter, 1980). A literatura está repleta de exemplos de empresas de baixo share com desempenho superior ao de empresas de share elevado (por exemplo, Inland Steel versus USX). Nesses casos, o market share pode ser um indicador de desempenho inferior se comparado a avaliações subjetivas que levem em conta a estratégia específica da empresa.

Em segundo lugar, é possível que o efeito da orientação para o mercado sobre o market share seja retardado, isso é, que a orientação para o mercado leve a maior market share ao longo de um intervalo de tempo relativamente longo. Nesse caso, esses efeitos podem deixar de ser captados pela concepção de corte longitudinal do estudo. Com base nessas considerações, os autores tendem a dar mais credibilidade a resultados obtidos por meio das medidas subjetivas de desempenho. Os resultados também sugerem que a qualidade do produto não está relacionada com market share, conclusão que diverge dos resultados obtidos com a base de dados PIMS.
Os resultados relatados nas Tabelas 3 e 4 dão forte sustentação aos efeitos da orientação para o mercado sobre o comprometimento organizacional dos funcionários $(b=0,44, p<0,001$, Amostra I; $b=0,66, p<$ 0,001 , Amostra II) e o seu espírito de classe ( $b=0,51, p$ $<0,001$, Amostra I; $b=0,58, p<0,001$, Amostra II). Isso dá a impressão de que a orientação para o mercado alimenta a formação de um elo entre os funcionários e a organização, e promove um sentimento de pertença a uma grande família organizacional dedicada a atender e superar as necessidades e expectativas do mercado.

Finalmente, examinamos os testes dos efeitos moderadores da turbulência do mercado, da intensidade competitiva e da turbulência tecnológica sobre a ligação entre orientação para o mercado e desempenho $\left(\mathrm{H}_{11}-\mathrm{H}_{13}\right)$. As diferenças entre os coeficientes de regressão associados à orientação para o mercado não são estatisticamente significativas $(p<0,05)$ entre ambientes caracterizados por níveis baixos e elevados das três variáveis moderadoras em ambas as amostras. Esses resultados não sustentam os efeitos moderadores de nenhuma das variáveis moderadoras. Em outras palavras, o elo entre a orientação para o mercado e o desempenho parece ser forte em todos os contextos caracterizados por diferentes graus de turbulência do mercado, intensidade competitiva e turbulência tecnológica. Por outro lado, é possível que os efeitos moderadores efetivamente existam mas não tenham sido detectados devido ao poder potencialmente insuficiente do teste estatístico, ao porte relativamente pequeno da amostra ou ao fato de as medidas de confiabilidade não serem suficientemente altas.

\section{CONCLUSÃO}

\section{Implicações administrativas}

O objetivo do estudo foi testar empiricamente diversas hipóteses propostas na literatura quanto aos antecedentes e às conseqüências da orientação para o mercado. As conclusões do estudo sugerem que a orientação de uma empresa para o mercado é uma importante determinante de seu desempenho, independentemente da turbulência do mercado, da intensidade da competição ou da turbulência tecnológica do ambiente em que opera. Assim, parece que os administradores deveriam aumentar a orientação de suas empresas para o mercado a fim de melhorar o desempenho operacional. É importante observar que, embora o estudo não tenha identificado uma relação entre orientação para o mercado e 
market share, essa conclusão deve ser fortalecida pelas considerações anteriormente discutidas.

O estudo sugere diversos fatores como determinantes importantes da orientação para o mercado. Mais especificamente, a orientação para o mercado parece ser facilitada pela ênfase a ela dada pela alta administração por meio de lembrança contínua aos funcionários do quanto é crítico que eles sejam sensíveis e respondam aos acontecimentos do mercado. Significativamente, a orientação para o mercado parece exigir certo nível de aceitação de risco por parte dos altos administradores e disposição para tolerar ocasionais fracassos de novos produtos e serviços como normais na vida empresarial. Na falta de tal disposição para aceitar riscos calculados, os funcionários dos níveis hierárquicos inferiores evitarão reagir aos acontecimentos do mercado com novos produtos, serviços ou programas.

Embora o papel da alta administração na formação da orientação para o mercado seja importante, parece que a natureza da dinâmica interdepartamental também tem função muito significativa na determinação do nível de orientação para o mercado de uma empresa. Dois fatores que parecem afetar a orientação para o mercado são a conectividade e o conflito interdepartamentais. O conflito interdepartamental parece reduzir a orientação para o mercado, enquanto a ligação parece ter papel facilitador. Assim, pode ser útil promover a conectividade por meio da proximidade física entre departamentos e por meio de telemática (conexão entre computadores e correio de voz). Embora um certo nível de conflito interdepartamental seja inerente à própria constituição dos diferentes departamentos, parece útil reduzir o nível de conflito por diversos meios, como programas de treinamento interdepartamentais, atividades interfuncionais e alinhamento de metas de desempenho, fazendo com que elas se voltem para o mercado buscando a satisfação do cliente.

O papel dos sistemas de recompensa baseados no mercado e da descentralização da tomada de decisões na criação de uma orientação para o mercado parece ser forte, sugerindo que os sistemas de recompensa devam levar em conta a contribuição individual para a captação e o atendimento das necessidades do mercado. Além disso, a relação negativa entre centralização e orientação para o mercado sugere ser útil dar poderes aos empregados para que tomem decisões nos níveis mais baixos da hierarquia, em vez de concentrálas nos escalões superiores. Embora a formalização e a departamentalização não pareçam afetar a orientação para o mercado, parece que o conteúdo das regras for- mais, e não sua mera presença, é a determinante mais importante da orientação para o mercado. Da mesma forma, a maneira como interagem os diversos departamentos parece ser mais importante como determinante da orientação para o mercado do que o simples número de departamentos existentes numa empresa.

\section{Indicações para pesquisa}

Parece haver diversas áreas que necessitam de mais pesquisas. Talvez a mais importante seja a avaliação do impacto de uma orientação para o mercado sobre o desempenho empresarial. Embora os resultados deste estudo sustentem uma relação entre orientação para o mercado e uma medida subjetiva de desempenho, a relação proposta entre orientação para o mercado e market share não encontrou respaldo. Nesse aspecto, é importante observar que o desempenho empresarial é um construto multidimensional e pode ser caracterizado de diferentes maneiras, inclusive pela eficácia, eficiência e adaptabilidade (veja Walker e Ruekert 1987). Ademais, o desempenho numa dimensão pode ir contra o desempenho em outras. Assim sendo, seria útil, em estudos futuros, explorar as complexidades da relação entre orientação para o mercado e dimensões alternativas de desempenho empresarial. Também seria conveniente avaliar a relação entre a orientação para o mercado e o desempenho empresarial no decorrer de prolongados períodos de tempo.

Em segundo lugar, seria desejável avaliar a influência de outros fatores sobre a orientação de uma organização para o mercado. Por exemplo, determinadas características dos funcionários, como personalidade e atitude, ajudam ou atrapalham a orientação para o mercado? No mesmo sentido, algumas das variáveis incluídas neste estudo merecem investigação mais detida. Por exemplo, embora, por hipótese, a formalização afete a orientação para o mercado, concluímos que não afeta nem a ela nem a nenhum de seus componentes. Há necessidade de pesquisa para avaliar as características das regras que facilitam ou atrapalham a orientação para o mercado.

Ademais, é possível argumentar que determinadas variáveis, com o conflito interdepartamental, modeladas no estudo como antecedentes da orientação para o mercado, também podem ser tratadas como conseqüências dela. Seria útil realizar estudos que avaliem o porte e a direção da relação entre conflito interdepartamental e orientação para o mercado. No mesmo sentido, parece provável que as variáveis ambientais aqui modeladas como moderadoras ajam conjuntamente 
para aumentar ou reduzir a importância da orientação para o mercado no desempenho empresarial. O porte limitado da amostra impede uma análise de tais efeitos moderadores em conjunto. Seria útil realizar tais análises em estudos vindouros para melhor entender as condições em que a orientação para o mercado é de particular importância para o desempenho empresarial.

Do ponto de vista metodológico, os dados do estudo foram obtidos de administradores graduados de cada unidade de negócio. Seria útil obter uma amostragem mais ampla de gestores, e até mesmo de não gestores, das unidades em estudos futuros. Isso minimizaria qualquer viés em potencial resultante do nível dos informantes. Além disso, seria muito interessante comparar as impressões de empregados em diferentes níveis hierárquicos de uma unidade de negócio e tomar conhecimento das diferenças de percepção, caso haja, quanto à orientação para o mercado. Também seria útil tentar mensurar a orientação para o mercado por meio de medidas não reativas, como a análise do conteúdo de memorandos internos, relatórios anuais e outros documentos, e relacioná-las com outras medidas de orientação para o mercado, como a usada neste estudo.

Finalmente, este estudo emprega uma análise em corte longitudinal de um grande número de empresas. Embora proporcione importantes esclarecimentos acerca das determinantes de uma orientação para o mercado, não esclarece muito os processos de mudança envolvidos no aprimoramento da orientação para o mercado. Por exemplo, um nível relativamente baixo de orientação para o mercado pode, com efeito, levar a administração a alterar determinados antecedentes, como o sistema de recompensas, o que, por sua vez, levaria a um nível mais elevado de orientação para o mercado. Sob esse aspecto, seria interessante realizar estudos aprofundados de um pequeno número de organizações envolvidas em processo de mudança para melhor entender os fatores que influenciam a iniciação e a implementação de esforços de mudança voltados para aprimorar a orientação para o mercado de uma empresa.

\section{APÊNDICE}

\begin{tabular}{|c|c|c|}
\hline ESCALA & ITENS DA ESCALA & $\begin{array}{l}\text { COEFICIENTE } \\
\text { ALFA }\end{array}$ \\
\hline \multirow[t]{10}{*}{$\begin{array}{l}\text { Orientação para o mercado } \\
\text { (geração de inteligência) }\end{array}$} & $\begin{array}{l}\text { 1. Nesta unidade de negócio, nos reunimos com os clientes pelo menos uma vez por } \\
\text { ano para descobrir de que produtos ou serviços precisarão no futuro. }\end{array}$ & 0,71 \\
\hline & $\begin{array}{l}\text { 2. } 0 \text { pessoal de nosso departamento industrial interage diretamente com os clientes } \\
\text { para saber como melhor atendê-los. }\end{array}$ & \\
\hline & 3. Nesta unidade de negócio, fazemos muitas pesquisas internas de mercado. & \\
\hline & 4. Demoramos a detectar mudanças nas preferências de nossos clientes por produtos. & \\
\hline & $\begin{array}{l}\text { 5. Pesquisamos os usuários finais pelo menos uma vez por ano para determinar a } \\
\text { qualidade de nossos produtos e serviços. }\end{array}$ & \\
\hline & $\begin{array}{l}\text { 6. Entrevistamos ou pesquisamos freqüentemente as pessoas que podem influenciar } \\
\text { as compras de nossos usuários finais (ex.: varejistas, distribuidores). }\end{array}$ & \\
\hline & $\begin{array}{l}\text { 7. Colhemos informações setoriais por meio de situações informais (ex.: almoços com } \\
\text { amigos do mesmo setor, conversas com parceiros comerciais). }\end{array}$ & \\
\hline & $\begin{array}{l}\text { 8. Em nossa unidade de negócio, a inteligência sobre concorrentes é gerada indepen- } \\
\text { dentemente por diversos departamentos. }\end{array}$ & \\
\hline & $\begin{array}{l}\text { 9. Demoramos a detectar mudanças fundamentais em nosso setor (ex.: competição, } \\
\text { tecnologia, regulação). }\end{array}$ & \\
\hline & $\begin{array}{l}\text { 10. Revemos periodicamente o provável efeito de mudanças em nosso ambiente de } \\
\text { negócios (ex.: regulação sobre a clientela). }\end{array}$ & \\
\hline $\begin{array}{l}\text { Orientação para o merca- } \\
\text { do (disseminação de inte- } \\
\text { ligência) }\end{array}$ & $\begin{array}{l}\text { 1. Grande parte das conversas informais em nossa unidade de negócio se refere às } \\
\text { táticas ou estratégias de nossos concorrentes. }\end{array}$ & 0,82 \\
\hline
\end{tabular}




\begin{tabular}{|l|}
\hline ESCALA \\
\hline \\
\hline \\
\hline Orientação para o mercado \\
(concepção de resposta) \\
\hline
\end{tabular}

Orientação para o mercado (implementação de resposta)
2. Temos reuniões interdepartamentais pelo menos uma vez por trimestre para discutir tendências e acontecimentos do mercado.

3. 0 pessoal de marketing de nossa unidade de negócio dedica tempo a discutir as necessidades futuras dos clientes com outros departamentos funcionais.

4. Nossa unidade de negócio faz circular periodicamente documentos (ex.: relatórios, boletins) que fornecem informações sobre nossos clientes.

5. Quando algo de importante acontece com um grande cliente ou mercado, toda a unidade de negócio logo fica sabendo.

6. Dados sobre satisfação dos clientes são regularmente disseminados em todos os níveis da unidade de negócio.

7. A comunicação entre marketing e os departamentos industriais sobre acontecimentos do mercado é mínima.

8. Quando um departamento descobre algo importante sobre os concorrentes, demora para alertar os demais.

1. Levamos uma eternidade para decidir como reagir às mudanças de preços de nossos concorrentes.

2. Em nossa unidade de negócio, os esforços de desenvolvimento de novos produtos são movidos por princípios de segmentação de mercado.

3. Por algum motivo, sempre tendemos a ignorar mudanças das necessidades de produtos ou serviços de nossos clientes.

4. Revemos periodicamente nossos esforços de desenvolvimento de produtos para nos certificarmos de que estejam alinhados com o que o cliente quer.

5. Nossos planos de negócio estão mais ligados a avanços tecnológicos do que a pesquisas de mercado.

6. Diversos departamentos se reúnem periodicamente para planejar respostas a mudanças havidas em nosso ambiente de negócio.

7. As linhas de produtos que vendemos dependem mais da política interna do que das necessidades efetivas do mercado.

1. Se um grande concorrente lançasse uma campanha intensiva voltada para nossos clientes, implementaríamos uma reação imediatamente.

2. As atividades dos diferentes departamentos desta unidade de negócio são bem coordenadas.

3. As reclamações dos clientes não são ouvidas nesta unidade de negócio

4. Mesmo que concebêssemos um excelente plano de marketing, provavelmente não conseguiríamos implementá-lo a tempo.

5. Reagimos rapidamente a mudanças significativas das estruturas de preços de nossos concorrentes.

6. Quando descobrimos que nossos clientes estão insatisfeitos com a qualidade de nossos serviços, tomamos medidas corretivas imediatamente.

7. Quando descobrimos que os clientes gostariam que modificássemos um produto ou serviço, os departamentos envolvidos envidam esforços coordenados nesse sentido.
COEFICIENTE ALFA

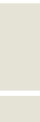




\begin{tabular}{|l|}
\hline ESCALA \\
\hline $\begin{array}{l}\text { Ênfase da alta } \\
\text { administração }\end{array}$ \\
\hline \\
\hline Aversão da alta \\
administração ao risco \\
\hline
\end{tabular}

Conflito interdepartamental

\section{Conectividade interdepartamental}

ITENS DA ESCALA

1. Os altos administradores dizem reiteradamente aos empregados que a sobrevivência desta unidade de negócio depende de sua adaptação às tendências do mercado. 2. Os altos administradores dizem freqüentemente aos empregados que devem ser sensiveis às atividades dos concorrentes.

3. Os altos administradores sempre dizem às pessoas daqui que precisam se preparar já para as necessidades futuras dos clientes.

4. De acordo com nossos altos administradores, atender ao cliente é a coisa mais importante para nossa unidade de negócio.

1. A alta administração desta unidade de negócio acredita que vale a pena assumir maiores riscos financeiros para atingir melhores resultados.

2. A alta administração aceita fracassos ocasionais de novos produtos como algo natural.* 3. A alta administração desta unidade de negócio gosta de assumir grandes riscos financeiros.

4. A alta administração incentiva o desenvolvimento de estratégias de marketing inovadoras, mesmo sabendo que algumas irão fracassar.

5. A alta administração gosta de "jogar seguro".

6. A alta administração só gosta de implementar planos se tiver certeza de que vão funcionar.

1. A maioria dos departamentos desta empresa se dá bem com os demais.

2. Quando se reúnem membros de diversos departamentos, 0 ambiente muitas vezes fica tenso.

3. As pessoas de um departamento não gostam de interagir com a de outros.

4. Os empregados de diferentes departamentos sentem que as metas de seus respectivos departamentos são harmônicas.

5. Proteger o território do próprio departamento é parte do modo de vida desta unidade de negócio.

6. Os objetivos do departamento de marketing são incompatíveis com os do departamento de produção.

7. 0 conflito interdepartamental desta unidade de negócio é baixo ou inexistente.

1. Nesta unidade de negócio é fácil falar com praticamente qualquer pessoa, independentemente de nível ou posição.

2. Nesta unidade de negócio há muitas oportunidades de conversa informal entre as pessoas de diferentes departamentos.

3. Nesta unidade de negócio os empregados de diferentes departamentos se sentem à vontade para falar uns com os outros quando há necessidade.

4. Os gestores daqui desencorajam a discussão de assuntos ligados ao trabalho com qualquer pessoa que não seja um superior ou subordinado imediato.

5. As pessoas aqui são muito acessíveis aos membros de outros departamentos.

6. A comunicação entre um departamento e outro deve passar pelos "canais regulares".

7. Os administradores menos graduados de meu departamento podem marcar facilmente reuniões com administradores menos graduados de outros departamentos.
COEFICIENTE

ALFA

0,66

0,85

0,87

0,80 


\begin{tabular}{|l|}
\hline ESCALA \\
\hline Formalização \\
\hline \\
\hline Centralização \\
\hline Comprometimento \\
\hline organizacional \\
\hline recompensas \\
\hline
\end{tabular}

ITENS DA ESCALA

2. As pessoas podem tomar suas próprias decisões sem consultar mais ninguém.

3. A maneira como as coisas são feitas aqui depende de quem as faz.

4. As pessoas daqui podem fazer quase tudo o que quiserem.

5. A maioria das pessoas daqui cria suas próprias regras de trabalho.

6. Os empregados são supervisionados constantemente em busca de infrações às regras.

7. As pessoas daqui se sentem sob constante vigilância para garantir que obedeçam a todas as regras.

1. Pouca coisa pode ser feita por aqui sem a aprovação de um supervisor.

2. Aqui, pessoas que queiram tomar suas próprias decisões são logo desencorajadas.

3. Até assuntos sem importância precisam ser encaminhados a alguém hierarquicamente superior para obterem resposta definitiva.

4. Preciso consultar meu chefe antes de fazer quase qualquer coisa.

5. Qualquer decisão que eu tome tem que ser aprovada pelo meu chefe.

1. Independentemente do departamento em que trabalhem, as pessoas desta unidade de negócio são reconhecidas por perceberem as movimentações dos concorrentes.

2. As avaliações de satisfação do cliente influenciam a remuneração dos altos administradores desta unidade de negócio.

3. São oferecidas recompensas formais (como aumentos e promoções) a quem forneça consistentemente boa inteligência de mercado.

4. 0 desempenho dos vendedores desta unidade de negócio é medido pela força dos relacionamentos construídos com os clientes.

5. A remuneração dos vendedores se baseia quase exclusivamente no volume de vendas.

6. Usamos pesquisas com clientes para avaliar nossos vendedores.

1. Os empregados têm a sensação de que seu futuro está intimamente associado ao da organização.

2. Os empregados fariam sacrifícios pessoais com prazer se isso fosse importante para o bem-estar da unidade de negócio.

3. Os elos entre esta organização e seus empregados são fracos.

4. De modo geral, os empregados se orgulham de trabalhar para esta unidade de negócio.

5. Os empregados freqüentemente vão acima e além do dever para garantir o bemestar desta unidade de negócio.

6. 0 comprometimento do nosso pessoal com esta unidade de negócio é baixo ou inexistente.

7. Fica evidente que os empregados gostam desta unidade de negócio.

Espírito de classe

1. Todas as pessoas desta unidade de negócio se preocupam realmente com o bemestar e com os problemas de todas as demais.

2. Todos os níveis da unidade de negócio são unidos por um espírito de equipe.

3. Trabalhar para esta unidade de negócio é como ser parte de uma grande família.

4. As pessoas desta unidade de negócio são emocionalmente ligadas umas às outras.

(1) 


\begin{tabular}{|c|c|c|}
\hline \multirow[t]{4}{*}{ ESCALA } & ITENS DA ESCALA & $\begin{array}{l}\text { COEFICIENTE } \\
\text { ALFA }\end{array}$ \\
\hline & 5. As pessoas desta unidade de negócio sentem que "estão nisso juntas". & \\
\hline & 6. Esta unidade de negócio carece de espírito de classe. & \\
\hline & $\begin{array}{l}\text { 7. As pessoas desta unidade de negócio se consideram indivíduos independentes que } \\
\text { precisam tolerar os outros que os cercam. }\end{array}$ & \\
\hline \multirow[t]{2}{*}{ Desempenho geral } & 1. Desempenho geral da unidade de negócio no ano anterior. & 0,83 \\
\hline & 2. Desempenho geral em relação aos principais concorrentes no ano anterior. & \\
\hline \multirow[t]{6}{*}{ Turbulência do mercado } & $\begin{array}{l}\text { 1. Em um negócio como o nosso, as preferências dos clientes quanto aos produtos } \\
\text { mudam significativamente com o passar do tempo. }\end{array}$ & 0,68 \\
\hline & 2. Nossos clientes tendem a procurar novos produtos o tempo todo. & \\
\hline & $\begin{array}{l}\text { 3. Às vezes nossos clientes são muito sensíveis aos preços, mas em outros casos } 0 \\
\text { preço é de importância relativamente baixa. }\end{array}$ & \\
\hline & $\begin{array}{l}\text { 4. Estamos percebendo demanda por nossos produtos e serviços entre clientes que } \\
\text { jamais os compraram antes. }\end{array}$ & \\
\hline & $\begin{array}{l}\text { 5. Novos clientes tendem a ter necessidades relacionadas a produtos diferentes das } \\
\text { apresentadas por nossos clientes. }\end{array}$ & \\
\hline & 6. Muitos dos clientes que atendemos já foram atendidos por nós anteriormente. & \\
\hline \multirow[t]{6}{*}{ Intensidade competitiva } & 1. A competição é predatória em nosso setor. & 0,81 \\
\hline & 2. Há muitas “guerras de promoção" em nosso setor. & \\
\hline & $\begin{array}{l}\text { 3. Qualquer coisa que um competidor ofereça pode ser prontamente replicada pelos } \\
\text { demais. }\end{array}$ & \\
\hline & 4. A competição nos preços é marca registrada do nosso setor. & \\
\hline & 5. Sabemos quase todos os dias de alguma nova movimentação dos concorrentes. & \\
\hline & 6. Nossos concorrentes são relativamente fracos. & \\
\hline \multirow[t]{5}{*}{ Turbulência tecnológica } & 1. A tecnologia do nosso setor está mudando rapidamente. & 0,88 \\
\hline & 2. As mudanças tecnológicas representam grandes oportunidades no nosso setor. & \\
\hline & 3. É muito difícil prever onde a tecnologia do nosso setor estará daqui a 2 ou 3 anos.* & \\
\hline & $\begin{array}{l}\text { 4. No nosso setor, grande parte das idéias de novos produtos só foi possível por causa } \\
\text { de rupturas tecnológicas. }\end{array}$ & \\
\hline & 5. Os avanços tecnológicos no nosso setor são relativamente pequenos. & \\
\hline
\end{tabular}

* Item eliminado por causa do procedimento de refinamento de escala descrito no texto.

\section{NOTA}

Os autores manifestam seu agradecimento a Tom Kinnear por sua orientação, e a três revisores anônimos e Rick Staelin por suas úteis sugestões. Reconhecem ainda, com gratidão, o apoio recebido do Marketing Science Institute e da Escola de Administração de Empresas da Universidade do Texas - Austin. Os autores forneceram contribuições equivalentes ao texto.

\section{REFERÊNCIAS BIBLIOGRÁFICAS}

AIKEN, M.; HAGE, J. Organizational independence and intraorganizational structure. American Sociological Review, v. 33, p. 912-30, 1968.
AIKEN, M.; HAGE, J. Organizational alienation. American Sociological Review, v. 31, p. 497-507, 1966.

ANDERSON, P.; CHAMBERS, T. A reward/measurement model of organizational buying behavior. Journal of Marketing, v. 49, n. 2, p. 7-23, 1985.

ARNOLD, H. H. Moderator variables: a clarification of conceptual, analytic and psychometric issues. Organizational Behavior and Human Performance, v. 29 , n. 2, p. 143-74, 1982

BARKSDALE, H. C.; DARDEN, B. Marketers' attitude toward the marketing concept. Journal of Marketing, v. 35, n. 4, p. 29-36, 1971 
BENNET, R.; COOPER, R. Beyond the marketing concept. Business Horizons, v. 22, n. 3, p. 76-83, 1981.

BITNER, M. J. Evaluating service encounters: the effects of physical surroundings and employee responses. Journal of Marketing, v. 54, n. 2, p. 69-82, 1990.

BORCH, F. J. The marketing philosophy as a way of business life. In: MARNiNG, E.; NEWGARDEN, A. (Eds.). The Marketing Concept: Its Meaning to Management. New York: American Management Association, p. 3-16, 1957

BOULDING, W.; STAELIN, R. Environment, market share, and market power. Management Science, v. 36, n. 10, p. 1160-77, 1990.

CHOW, G. C. Tests of equality between sets of coefficients in two linear regressions. Econometrika, v. 28, p. 591-605, 1960.

CHURCHILL, G. A. A paradigm for developing better measures of marketing constructs. Journal of Marketing Research, v. 16, n. 1, p. 64-73, 1979.

CRONBACH, L. J. et al. Toward Reform in Program Evaluation. San Francisco: Jossey Bass., 1981.

DAY, G. Market Driven Strategy: Processes for Creating Value. New York: The Free Press, 1990.

DAY, G.; WENSLEY, R. Assessing advantage: a framework for diagnosing competitive superiority. Journal of Marketing, v. 52, n. 2, 1-20, 1988.

DESHPANDE, R.; FARLEY, J. U.; WEBSTER JR., F. E. corporate culture, customer orientation and innovativeness in Japanese firms: a quadrad analysis. Journal of Marketing, v. 57, n. 1, p. 23-7, 1933.

DESHPANDE, R.; ZALTMAN, G. Factors affecting the use of market research information: a path analysis. Journal of Marketing Research, v. 19, n. 1, p. 14-31, 1982.

DESHPANDE, R.; WEBSTER Jr., F. E. Organizational culture and marketing: defining the research agenda. Journal of Marketing, v. 53, n. 1, p. 315, 1989.

FELTON, A. P. Making the marketing concept work. Harvard Business Review, v. 37, n. 4, p. 55-65, 1959.

GASKI, J. F. The theory of power and conflict in channels of distribution. Journal of Marketing, v. 48, n. 3, p. 9-29, 1984.

HAGE, J.; AIKEN, M. Social Change in Complex Organizations. New York: Random House, 1970.

HALL, R. H.; HASS, J. E.; JOHNSON, N. J. Organizational size, complexity and formalization. American Sociological Review, v. 32, n. 6, p. 903-12, 1967.

HAMBRICK, D. C.; MASON, P. A. Upper echelons: the organization as a reflection on its top managers. Academy of Management Review, v. 9, n. 2, 193-206, 1984.

HISE, R. T. Have manufacturing firms adopted the marketing concept? Journal of Marketing, v. 29, n. 3, p. 9-12, 1965.
HOPWOOD, A. Accounting and Human Behavior. London: Haymarket Publishing, 1974.

HOUSTON, F. S. The marketing concept: what it is what it is not. Journal of Marketing, v. 50, p. 81-7, 1986.

JACOBSON, R.; AAKER, D. A. The strategic role of product quality. Journal of Marketing, v. 51, n. 4, p. 31-44, 1987.

JAWORSKI, B. J. Toward a theory of marketing control: environmental contexts, control types, and consequences. Journal of Marketing, v. 52, n. 3, p. 23-39, 1988.

KALDOR, A. G. Imbricative marketing. Journal of Marketing, v. 35, n. 2, p. $19-25,1971$

KOHLI, A. K.; JAWORSKI, B. J. Market orientation: the construct, research propositions, and managerial implications. Journal of Marketing, v. 54, n. 2, p. 1-18, 1990

LAWLER, E. F; RHODE, J. G. Information and Control in Organizations. Pacific Palisades, CA: Goodyear Publishing Company, 1976.

LEVITT, T. The Marketing Mode. New York: McGraw-Hill, 1969.

LINDEN, W. J. Marketing Marketing: The Ryder System Story. Estudo apresentado na miniconferência do Marketing Science Institute sobre Desenvolvimento de Uma Orientação para o Mercado. Cambridge: MA, 1987.

LUNDSTROM, W. J. The marketing concept: the ultimate in bait and switch. Marquette Business Review, v. 20, p. 214-30, 1976.

LUSCH, R. F; UDELL, J. G.; LACZNIAK, G. R. The practice of business. Business Horizons, v. 19, p. 65-74, 1976

LUSCH, R. F.; LACZNIAK, G. R. The evolving marketing concept, competitive intensity and organizational performance. Journal of the Academy of Marketing Science, v. 15, n. 3, p. 1-11, 1987.

MCKITTERICK, J. B. What is the marketing management concept? In: BASS, F. M. (Eds.). The Frontiers of Marketing Thought and Science, Chicago American Marketing Association, p. 71-92, 1957.

MCNAMARA, C. P. The present status of the marketing concept. Journal of Marketing, v. 36, n. 1, p. 50-7, 1972.

NARVER, J. C.; SLATER, S. F. The effect of a market orientation on business profitability. Journal of Marketing, v. 54, n. 4, p. 20-35, 1990.

NARVER, J. C.; SLATER, S. F. Becoming more market oriented: an exploratory study of programmatic and market-back approaches. Working paper, University of Washington, 1991.

NUNNALLY, J. C. Psychometric Theory. New York: McGraw-Hill, 1978.

OLSON, D. When consumer firms develop a marketing orientation. Estudo apresentado na miniconferência da MSI sobre Desenvolvimento de uma Orientação para o Mercado. Cambridge: MA, 1987.

PARASURAMAN, A.; ZEITHAML, V. A.; BERRY, L. L. A conceptual model of service quality and its implications for future research. Journal of Marketing, v. 49, n. 4, p. 41-50, 1985. 
PATTON, M. Q. Utilization Focused Evaluation, Beverly Hills, CA: Sage Publications, 1978.

PORTER, M. E. Competitive Strategy. New York: The Free Press, 1980.

RAVE, B. H.; KRUGLANSKI, A. W. Conflict and power. In: SWINGLE, P. (Eds.). The Structure of Conflict. New York: Academic Press, 1970. p. 69109.

RUEKERT, R. W.; WALKER JR., O. C. Marketing's interaction with other functional units: a conceptual framework and empirical evidence. Journal of Marketing, v. 51, n. 1, p. 1-19, 1987.

SHAPIRO, B. P. What the hell is 'market oriented'? Harvard Business Review, v. 66, p. 119-25, 1988.

SILK, A. J.; KALWANI, M. U. Measuring influence in organizational purchase decisions. Journal of Marketing Research, v. 19, n. 2, p. 165-81, 1982

STAMPFL, R. W. Structural constraints, consumerism, and the marketing concept. MSU Business Topics, v. 26, p. 5-16, 1978.

TAUBER, E. M. How marketing discourages major innovation. Business Horizons, v. 17, p. 22-6, 1974

WALKER, O. C., JR.; RUEKERT, R. W. Marketing's role in the implementation of business strategies: a critical review and conceptual framework. Journal of Marketing, v. 51, n. 3, p. 15-33, 1987.
WEBSTER, F. E., JR. Rediscovering the marketing concept. Business Horizons, v. 31, p. 29-39, 1988.

ZALTMAN, G.; DUNCAN, R.; HOLBEK, J. Innovations and Organizations. New York: John Wiley and Sons, Inc., 1973.

ZALTMAN, G.; LEMASTERS, K.; HEFFRING, M. Theory Construction in Marketing. New York: John Wiley and Sons, Inc., 1982.

Este artigo é de propriedade exclusiva da American Marketing Association, tanto quanto sua licença para uso, e é protegida pelo Copyright e pelas leis de propriedade intelectual. O uso deste material é dirigido para uso pessoal e não comercial. Qualquer outro tipo de uso deste artigo é estritamente proibido. O usuário não poderá modificar, publicar, transmitir, participar na transferência ou na venda do material, reproduzir, criar trabalhos derivados (incluindo material didático) deste, distribuir, realizar apresentação, ou qualquer modo de utilização do conteúdo inteiro ou em partes. Este artigo, protegido pelo Copyright, foi traduzido objetivando expressamente a essa publicação. A American Marketing Association não assumirá a responsabilidade por erros de interpretação causados pela tradução. Este artigo foi reproduzido com a autorização do Journal of Marketing, publicado pela American Marketing Association. O artigo "Market orientation: antecedents and consequences", dos autores Bernard J. Jaworski e Ajay K. Kohli, foi originalmente publicado no Journal of Marketing, volume 57 (July 1993), p. 53-70.

\title{
Artigo convidado. Aprovado em 01.02.2006.
}

\section{Bernard J. Jaworski}

Co-fundador da Marketspace e presidente do Monitor Executive Development.

Interesses de pesquisa nas áreas de orientação para o mercado, Internet e estratégia de marketing, comércio eletrônico, estratégias em economias em rede.

E-mail: bjaworski@marketspaceglobal.com

Endereço: Two Canal Park, Cambridge, Massachusetts - USA, 02141.

\author{
Ajay K. Kohli \\ Professor de Marketing na Goizueta Business School - Emory University. \\ Interesses de pesquisa nas áreas de orientação para o mercado, gestão de equipe de vendas, marketing de \\ commodity, organização para o marketing. \\ E-mail: ajay_kohli@bus.emory.edu \\ Endereço: Goizueta Business School, Emory University, 1300 Clifton Road, Atlanta, GA - USA, 30322.
}

